\title{
Monoclonal antibodies as therapeutic agents in oncology and antibody gene therapy
}

\author{
Qi Zhang ${ }^{1}$, Guihua Chen ${ }^{1}$, Xinyuan Liu², Qijun Qian ${ }^{3}$ \\ ${ }^{1}$ Transplantation Research Institute of Sun Yat-sen University, The Third Affiliated Hospital of Sun Yat-Sen University, 600 Tianhe \\ Rd, Guangzhou 510630, China, ${ }^{2}$ Institute of Biochemistry and Cell Biology, Chinese Academy of Sciences, Shanghai 200031, China; \\ ${ }^{3}$ Laboratory of Viral and Gene Therapy, Eastern Hepatobiliary Surgery Hospital, Second Military Medical University, 225 Changhai \\ Rd, Shanghai 200438, China
}

Antibodies as therapeutic agents are mostly used in oncology, as illustrated by their applications in lymphoma, breast cancer or colorectal cancer. This review provides a brief historical sketch of the development of monoclonal antibodies for cancer treatment and summarizes the most significant clinical data for the best-established reagents to date. It also discusses strategies to improve the anti-tumor efficacy of antibody therapy, including antibody gene therapy and exploitation of bone marrow derived primary mesenchymal stem cells as the antibody gene transporter.

Cell Research (2007) 17: 89-99. doi: 10.1038/sj.cr.7310143; published online 23 January 2007

Keywords: monoclonal antibody, cancer, gene therapy

\section{Introduction}

The discovery of monoclonal antibodies (mAbs) in 1975 by Kohler and Milstein ushered in cancer treatment to a modern era of targeted therapy $[1,2]$. Therapeutic antibodies have become a major strategy in cancer therapy due to their ability to specifically bind to primary and metastatic cancer cells with high affinity. They elicit anti-tumor effects by complement-mediated cytolysis and antibody-dependent cell-mediated cytotoxicity, or by focused delivery of radiation or cellular toxins (conjugated antibodies) [3-5]. Initially, the overall clinical outcomes were poor due to immunogenicity of the murine antibody used in therapy, modulation of targeted antigens and poor ability of these antibodies to mediate sufficient antibody-dependent effector functions in humans. Technological advances designed to overcome these main limitations have accelerated the development of antibodies as therapeutics. Since 1997, there have been nine anti-cancer therapeutic antibodies approved by the FDA for sale in the USA. A large number

\footnotetext{
Correspondence: Qijun Qian

Tel: +86-21-35030677; Fax: +86-21-35030677;

E-mail: qianqj@sino-gene.cn
}

of additional therapeutic antibodies are in early or late stages of clinical development.

\section{Development of recombinant antibodies as cancer therapeutics}

Therapeutic $\mathrm{mAbs}$ are from the typical immunoglobulin $\mathrm{G}$ class (IgG), containing two heavy and two light chains. The first report of successful cloning of an immunoglobulin gene segment was published in 1977, nearly one decade after the discovery of restriction endonuclease. It took another few years before the first recombinant antibodies, also named as "chimeric" mAbs, were generated by fusing rearranged murine variable $\mathrm{V}(\mathrm{D}) \mathrm{J}$ gene segments of a mouse $\mathrm{mAb}$ to human constant domains, or as recombinant Fab fusion proteins by replacing the $\mathrm{Fc}$ fragment with an enzyme moiety $[6,7]$. Compared with murine mAbs, chimeric antibodies were capable of mediating antibodydependent cellular cytotoxicity with human effector cells, and/or activating the complement cascade very efficiently, both in vitro and in pre-clinical trials. The use of chimeric antibodies significantly reduced the human anti-mouse antibody (HAMA) responses, but did not eliminate them completely. 
In order to further decrease the immunogenicity of murine antibodies, the first mouse mAb was "humanized" in 1986 by grafting the gene segments encoding the six antigen-binding loops onto human framework regions [810]. Although this process further reduced or eliminated the HAMA responses, it was still necessary to further redesign the antibody in many cases in order to re-establish the required specificity and affinity of the original murine antibody. Another approach to reduce the immunogenicity of mouse mAbs was to replace the immunogenic epitopes in the murine variable domains with benign amino-acid sequences. The de-immunized variable domains are then genetically linked to human IgG constant domains to yield de-immunized antibodies. In addition, primatial antibodies that featured the human and monkey chimeric antibody structure were developed to further reduce their immunogenicity. As nearly exact copies of human antibodies, they could be administered repeatedly and continuously for the treatment of chronic diseases. Also, fully human antibodies have been developed using murine sources, phage antibody libraries for human Ig genes and transgenic techniques [11].

The approval of nine mAbs by the FDA for clinical tumor therapy signifies important progress in antibody study. They include rituximab $\left(\right.$ Rituxan $\left.^{\mathbb{R}}\right)$, ibritumomab $\left(\right.$ Zevalin $\left.^{\circledR}\right)$, ${ }^{131}$ I-tositumomab (Bexxar $\left.{ }^{\circledR}\right)$, gemtuzumab ozogamicin $\left(\right.$ Mylotarg $\left.^{\circledR}\right)$, alemtuzumab $\left(\right.$ Campath $\left.^{\circledR}\right)$, trastuzumab (Herceptin $^{\circledR}$ ), bevacizumab $\left(\right.$ Avastin $\left.^{\circledR}\right)$, cetuximab $\left(\right.$ Erbitux $\left.^{\circledR}\right)$ and panitumumab $\left(\right.$ Vectibix $\left.^{\circledR}\right)$. These $\mathrm{mAbs}$ can be divided into two groups according to their targets [12]. The first group is directed against antigens that are either specifically expressed by tumor cells, such as the Her-2/neu protein on breast cancer and other carcinomas, or are shared with normal cells, such as differential antigens (CD20, CD52, CD19, etc.). The aim of using this type of antibodies is to induce tumor death by neutralizing the effect of a growth factor, or by inducing apoptosis, or by activating effector mechanisms of the host. The second group of therapeutic mAbs targets the stroma-tumor interactions. A leading example of this group is an $\mathrm{mAb}$ that neutralizes vascular endothelial growth factor (VEGF), a tumor-derived growth factor that increases neo-angiogenesis and thus supports tumor growth. Neutralization of VEGF blocks angiogenesis and leads to tumor starvation. There are also other mAbs being tested, including those targeting VEGF receptors or neutralizing adhesion molecules or proteases used by the tumor cells to invade their environment.

Apart from these two groups of mAbs, there is another type of therapeutic $\mathrm{mAb}$ on clinical trial, which aims to potentiate immune reactions against tumors. It is now acknowledged that there are immune reactions in cancer patients against their tumors. It was strongly suggested 35 years ago in acute leukemia and demonstrated in viral-associated tumors, such as Burkitt lymphoma, cervical carcinoma or hepatocellular carcinoma. Recently, a study of about 1000 patients has established the case in colorectal cancer [13]. However, the immune reaction is inefficient in patients with growing cancers, and the efficacy of therapeutic vaccine is still low. Tumors use several mechanisms to escape the immune system. For example, they induce lymphocytes to inhibit the immune reactions. These immune suppressors, also called regulatory lymphocytes, express specific markers (CD25, CTLA-4) that could serve as targets of mAbs to inhibit or destroy these cells, allowing for a better immune response to the tumor. However, the first therapeutic trial using a human $\mathrm{mAb}$ directed against CTLA-4 showed that the therapeutic efficacy on cancer was accompanied by auto-immunity due to the fact that regulatory lymphocytes also control anti-self-reactivity [14]. Other ways by which tumors escape immune attacks include modulation of their surface antigens, inhibition of complement-mediated cytotoxicity and ectopic expression of Fcg receptors [15].

\section{Approved antibody therapeutics for malignancies}

The earliest and most successful clinical use of antibodies as anti-cancer therapeutics has been for the treatment of hematologic malignancies. Advances in recombinant technologies make it possible to generate more specific and higher affinity mAbs with reduced immunogenicity after humanization or de-immunization, which together with the emerging conjugation capabilities, have enabled antibody therapeutics to become a major weapon in the treatment of leukemia and lymphoma. Since 1997 there have been nine commercially available therapeutic mAbs approved by the FDA, among which five are being used for treatment of hematologic malignancies and the other four for solid tumors (Table 1).

\section{Rituximab (Rituxan ${ }^{\circledR}$ )}

Rituximab has arguably become the commercially most successful anti-cancer drug of all mAb types since the introduction of taxanes. Rituximab sales exceeded \$ 1700 million in the US in 2004. Rituximab, which targets the CD20 surface receptor that is strongly overexpressed in most B-cell lymphomas, is a chimeric, monoclonal IgG1 antibody that induces apoptosis, antibody-dependent cell cytotoxicity and complement-dependent cytotoxicity. Rituximab was originally used in aggressive recurrent or refractory non-Hodgkin's lymphoma (NHL), and has been incorporated later into numerous chemotherapy regimens with promising results since its approval by the FDA in 
Table 1 FDA-approved mAbs in oncology

\begin{tabular}{|c|c|c|c|c|}
\hline Product & Target & Type & Approved year & Indications \\
\hline $\begin{array}{l}\text { Rituximab } \\
\left(\text { Rituxan }^{\circledR}\right)\end{array}$ & CD20 & Chimeric IgG1 & 1997 & B-cell lymphoma \\
\hline $\begin{array}{l}\text { Trastuzumab } \\
\left(\text { Herceptin }^{\circledR}\right)\end{array}$ & HER2/neu & Humanized IgG1 & 1998 & Breast cancer \\
\hline $\begin{array}{l}\text { Gemtuzumab } \\
\left(\text { Mylotarg }^{\circledR}\right)\end{array}$ & CD33 & Humanized IgG4-toxin-conjugate & 2000 & Acute myeloid leukemia \\
\hline $\begin{array}{l}\text { Alemtuzumab } \\
\text { (MabCampath }^{\circledR} \text { ) }\end{array}$ & CD52 & Humanized IgG1 & 2001 & Chronic lymphatic leukemia \\
\hline $\begin{array}{l}{ }^{90} \text { Y-ibritumomab } \\
\left(\text { Zevalin }^{\circledR}\right)\end{array}$ & CD20 & Murine IgG1-radionuclide-conjugate & 2002 & B-cell lymphoma \\
\hline $\begin{array}{l}{ }^{131} \text { I-tositumomab } \\
\left(\text { Bexxar }^{\circledR}\right)\end{array}$ & CD20 & Murine IgG1-radionuclide-conjugate & 2003 & B-cell lymphoma \\
\hline $\begin{array}{l}\text { Bevacizumab } \\
\left(\text { Avastin }^{\circledR}\right)\end{array}$ & VEGF & Humanized IgG1 & 2004 & Colorectal cancer \\
\hline $\begin{array}{l}\text { Cetuximab } \\
\left(\text { Erbitux }^{\circledR}\right)\end{array}$ & EGFR & Chimeric IgG1 & 2004 & Colorectal cancer \\
\hline $\begin{array}{l}\text { Panitumumab } \\
\left(\text { Vectibix }^{\circledR}\right)\end{array}$ & EGFR & Entirely human IgG2 & 2006 & Colorectal cancer \\
\hline
\end{tabular}

1997. Today, more than 540000 patients globally have received rituximab as part of more than 200 completed, ongoing or planned clinical trials. Rituximab has recently been approved to be administered as either a 4- or an 8 -dose weekly regimen in patients who have previously responded to rituximab, and in patients who have bulky tumors $(>10 \mathrm{~cm})$. A multicenter, open-label, single-arm study was conducted in 166 patients, with relapsed or refractory low-grade or follicular B-cell NHL, who received 4 weekly doses of $375 \mathrm{mg} / \mathrm{m}^{2}$ of Rituxan (given as an i.v. infusion). Thirteen patients with tumor masses $>10 \mathrm{~cm}$ or with $>5000$ lymphocytes $/ \mu 1$ in the peripheral blood were excluded from the study [16]. The overall response rate (ORR) was $50 \%$, with $6 \%$ complete response (CR) and $44 \%$ partial response (PR) rates. The median time to onset of response was 50 days and the median duration of response was 11.2 months. Disease-related signs and symptoms were present in $23 \%(39 / 166)$ of the patients at the study entry, and among these 64\% (25/39) showed resolution of symptoms. In another study, prolonging the standard treatment from 4 weekly doses to 8 did not lead to a higher response rate but prolonged response duration [17]. Thirty-seven patients with relapsed or refractory, low-grade NHL received 8 weekly doses of $375 \mathrm{mg} / \mathrm{m}^{2}$ of Rituxan. The ORR was $57 \%$ (CR 14\%, PR 43\%), with a projected median duration of response of 13.4 months.

Based on in vitro data suggesting synergistic actions of rituximab and cytotoxic agents including anthracyclines [18], the combination of six cycles of chemotherapy consisting of CHOP (cyclophosphamide, adriamycin, oncovin and prednisone) with concurrently administered rituximab in 40 patients with predominantly untreated follicular lymphoma greatly increased the response rate $(55 \% \mathrm{CR}$, $40 \%$ PR), suggesting synergistic actions with no significant additional toxicity [19]. Median time to disease progression was recently determined to be 82.3 months [20]. Results are comparable if, instead of parallel administration, CHOP is followed by rituximab [21]. The combination of rituximab with chemotherapy containing purine analogs, such as fludarabine, further increased the CR rate to $80 \%$ [22]. The superiority in achieving $\mathrm{CR}$ with combinations containing purine analogs is supported by a trial published in abstract form comparing fludarabine/mitoxantrone with rituximab consolidation to $\mathrm{CHOP} /$ rituximab showing $\mathrm{CR}$ rates of $87 \%$ and $76 \%$, respectively [23]. Recently, there has been increasing interest in using rituximab as a first-line therapy. Arguments in favor of this approach include its excellent toxicity profile, the presumed low rate of secondary malignancy and a lack of stem cell toxicity. In a phase II study, 62 patients with indolent NHL, most of whom suffered from follicular lymphoma, were treated with rituximab as the first-line drug at the standard 4 weekly doses of $375 \mathrm{mg} / \mathrm{m}^{2}$ [24]. Patients achieving an objective remission received maintenance treatment of rituximab every 6 months for a 
maximum of 2 years. The ORR was $73 \%$ (CR 37\%, PR $36 \%$ ) and the median actuarial progression-free survival was 34 months, which were clearly better than those in pre-treated patients.

The main toxicities associated with rituximab included infusion-related chills, fever, nausea, vomiting and general fatigue. Bone marrow suppression was not a significant side effect in patients treated with rituximab.

\section{${ }^{90}$ Y-ibritumomab (Zevalin ${ }^{\circledR}$ )}

The Zevalin ${ }^{\circledR}$ (ibritumomab tiuxetan) therapeutic regimen is a cancer therapy for patients with relapsed or refractory low-grade, follicular or transformed B-cell NHL, and also for patients with follicular B-cell NHL that is refractory to Rituxan ${ }^{\circledR}$ (rituximab) therapy. Zevalin is the first agent in a new class of targeted cancer treatments called radio-immunotherapies. It is composed of the murine version of the anti-CD20 mAb rituximab that has been covalently linked to the metal chelator, MD-DTPA, permitting stable binding of ${ }^{111}$ In when used for radionuclide tumor imaging and ${ }^{90} \mathrm{Y}$ when used to produce enhanced targeted cytotoxicity. The safety and efficacy of the Zevalin therapeutic regimen was evaluated in two pivotal multicenter clinical trials conducted in the US [25]. ORR was measured based on standardized NHL tumor shrinkage criteria (International Workshop Response Criteria - IWRC). The first efficacy study involved 54 patients with relapsed follicular NHL who failed to respond to Rituxan, the ORR to Zevalin treatment was $74 \%$, with $15 \%$ of the patients achieving a complete remission. Many of the patients participating in this trial were heavily pre-treated (with a median of four prior anti-cancer regimens) and had large or "bulky" tumors. For this population of patients who had essentially exhausted other available treatment options, Zevalin was shown to be highly effective. The second pivotal study, a phase III randomized, controlled trial, was conducted among 143 patients with relapsed or refractory low-grade follicular or transformed B-cell NHL [26]. Of them, 73 patients who received the Zevalin therapeutic regimen (which includes Rituxan) showed an $80 \%$ ORR, compared to $56 \%$ ORR in the remaining 70 patients who received Rituxan alone. Thirty percent of Zevalin-treated patients achieved a complete remission and $4 \%$ achieved an unconfirmed complete remission to therapy, compared to $16 \%$ complete remission for patients treated with Rituxan only (4\% achieved an unconfirmed complete remission), according to the IWRC. In addition to the two pivotal trials, a phase II study of 30 patients was conducted to study the safety and efficacy of a reduced dose of Zevalin in patients with low blood platelet counts (mild thrombocytopenia) [27]. While the risk and incidence of hematologic toxicity were higher among this already compromised group than in the two other trials, patients responded well to the Zevalin regimen, showing a $67 \%$ ORR without an increase in non-hematological adverse events. However, there was a greater incidence of hematologic toxicity than in the two pivotal studies.

${ }^{90}$ Y-ibritumomab received the orphan drug status and was approved by the FDA for the treatment of relapsed/refractory B-cell NHL in 2002, including patients with rituximab-refractory diseases. Treatment with the radiolabeled anti-CD20 antibody seems to produce a somewhat higher response rate compared to treatment with "naked" antibody; however, this does not lead to increased survival. There is considerable toxicity compared with rituximab, and there are also ongoing concerns regarding the long-term safety of radiation exposure.

\section{${ }^{131}$ I-tositumomab $\left(\right.$ Bexxar $\left.^{\circledR}\right)$}

Another radio-immunotherapeutic agent targeting the CD20 antigen is ${ }^{131}$ I-labeled tositumomab. Due to the highly variable elimination of ${ }^{131} \mathrm{I}$ in different patients, it is necessary to calculate each patient's individual dose, with a target total body radiation dose of $75 \mathrm{cGy}$. The nature of ${ }^{131} \mathrm{I}$ as a combined $\beta$ - and $\gamma$-emitter with the $\gamma$-radiation penetrating tissues up to $1 \mathrm{~m}$ allows dosimetry analysis of the therapeutic drug. The downside of this effect is that the total body dose delivered to the patients by the drug is higher than by its ${ }^{90} \mathrm{Y}$-carrying counterpart ${ }^{90} \mathrm{Y}$-ibritumomab. Patients receiving the drug should avoid close contact with other people and stay away from the public for 3-4 days due to their emission of radiation. Similar to ${ }^{90} Y$-ibritumomab, ${ }^{131}$ I-tositumomab administration is preceded by an infusion of the unlabeled antibody rituximab.

Clinical trials with ${ }^{131}$ I-tositumomab preceded those with ${ }^{90} \mathrm{Y}$-ibritumomab, and therefore longer follow-up and more reliable information of long-term toxicity are available. Similar numbers of patients have been treated with ${ }^{131}$ I-tositumomab, and the results of non-myeloablative radioimmunotherapy (RIT) with the drug are comparable to what is achieved with ${ }^{90} \mathrm{Y}$-ibritumomab. An ORR of $71 \%$ was achieved in a trial with 59 patients with relapsed or refractory advanced lymphoma. Median survival of responders was 12 months [28]. In a trial enrolling 24 patients with relapsed low-grade NHL, a myeloablative dose of ${ }^{131}$ I-tositumomab was administered. Apart from the expected marrow toxicity, effects on other organs were acceptable and considerably lower than in conventional myeloablative therapy. The ORR was $87 \%$ with a CR rate of $81 \%$ [29]. In a retrospective analysis of 125 patients receiving autologous stem cell transplants after either myeloablative RIT or a combination of total body irradiation and high-dose chemotherapy, the overall 5-year survival 
was significantly higher in the RIT group (67\% vs 53\%) [30]. In 2003, ${ }^{131}$ I-tositumomab was approved by the FDA for the non-myeloablative treatment of patients with B-cell NHL refractory to rituximab.

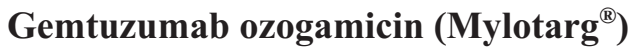

Gemtuzumab-ozogamicin (GO) is a humanized antibody to CD33 conjugated with calicheamycin, a highly potent cytotoxic antibiotic. CD33 is expressed on leukemic blast cells in most patients with acute myeloid leukemia (AML) and myelodyplastic syndrome (MDS). After administration, the antibody portion binds to CD33 and forms a complex that is internalized by the target cells. Following endocytosis, calicheamycin migrates into the nucleus producing double-strand breaks that ultimately result in cell death.

One hundred and forty-two patients with untreated first relapse of AML were subsequently enrolled in three multicentre phase II studies [31]. Patients received two doses of $9 \mathrm{mg} / \mathrm{m}^{2} \mathrm{GO}$, with the second administration being given 2 weeks after the first treatment. The overall remission rate was $30 \%$, consisting of $16 \% \mathrm{CR}$ and $14 \% \mathrm{CR}$ without platelet recovery (CRp). Median time to remission was 60 days, and median length of remission was 7.2 months in patients achieving CR, and 4.4 months in patients achieving CRp. In a recent trial, 51 patients over 65 years with untreated AML or advanced MDS were randomized to receive single agent GO or GO and Interleukin 11 [32]. An $8 \%$ CR was achieved in patients who received standard GO alone and 36\% in patients who received GO and IL-11. In a phase II trial in 49 patients $<65$ years with de novo AML, addition of one dose of $6 \mathrm{mg} / \mathrm{m}^{2} \mathrm{GO}$ to the standard induction treatment consisting of idarubicin/cytarabine led to a CR rate of $84 \%$ [33]. On the basis of the above data, GO achieved the orphan drug status and was approved by the FDA for the treatment of patients $\geq 60$ years with relapsed AML who were not considered to be candidates for standard cytotoxic therapy.

Side effects were more common and pronounced than those usually observed with "naked" antibodies: fever and chills occurred in $80 \%$ of patients, and grade 3 or 4 elevation of transaminases was observed in $20 \%$ of the patients. Severe thrombocytopenia and neutropenia developed in most of the patients. Hepatic veno-occlusive disease was found in $12 \%$ of the patients who received GO [34].

\section{Alemtuzumab (Campath $\left.{ }^{\circledR}\right)$}

Campath $^{\circledR}$ (alemtuzumab) is a recombinant DNA-derived humanized $\mathrm{mAb}$ binding to $\mathrm{CD} 52$, an antigen with unknown function found on $>95 \%$ of peripheral blood lymphocytes and monocytes, and to a smaller extent on granulocytes and in the male genital tract. Most B- and some T-cell lymphomas highly express CD52, whereas the protein is absent on bone marrow progenitor cells.

Ninety-three patients with chronic lymphocytic leukemia (CLL), after prior therapy with an alkylating agent and without response to fludarabine, were treated with increasing doses of Campath-1 $\mathrm{H}$ (target dose $30 \mathrm{mg}$, three times weekly for a maximum of 12 weeks) [35]. Overall response was $33 \%(2 \% \mathrm{CR}, 31 \% \mathrm{PR})$ and median time to disease progression was 9.5 months for responders. Despite that infection, prophylaxis was put in force beginning on day 8 and continuing for a minimum of 2 months after treatment, and grade 3 or 4 infections were reported in $27 \%$ of the heavily pre-treated patients, including pneumocystis and aspergillus pneumonia, systemic candidiasis, cryptococccal pneumonia and listeria meningitis leading to death in 11 patients. Based on these data and other trials $[36,37]$, alemtuzumab received the orphan status and was approved by the FDA for the treatment of CLL refractory to fludarabine in 2001.

Combination of alemtuzumab with other mAbs such as rituximab is another approach to enhance response rates. In the largest retrospective analysis including 48 patients with relapsed or refractory NHL, most of whom had CLL, the ORR was $52 \%$ in patients who received combined rituximab/alemtuzumab [38].

Apart from CLL, the most promising indication for alemtuzumab is T-prolymphocytic leukemia. A retrospective analysis of 76 T-prolymphocytic leukemia patients treated with alemtuzumab showed an ORR of $51 \%$, with a $40 \%$ complete response [39]. However, the median duration of CR was shorter than 8.7 months, and the outcome was unsatisfactory if no other treatment followed. Nevertheless, it opens a window of opportunity for allogeneic stem cell transplantation in patients eligible for this type of treatment.

\section{Trastuzumab (Herceptin ${ }^{\circledR}$ )}

The proto-oncogene human epidermal growth factor receptor (HER2 or c-erbB-2) encodes the HER2 receptor, a transmembrane protein found on numerous epithelial tissues and over-expressed in 20 to $30 \%$ of breast cancers. Herceptin ${ }^{\circledR}$ (trastuzumab) is a humanized IgG1 antibody targeting the HER2 protein. An international open-label study included 222 patients with HER2 over-expressing metastatic breast cancers that had progressed after one or two chemotherapy regimens [40]. HER2 status was assessed by immunohistochemistry. The patients were treated with trastuzumab as a single-agent therapy with a loading dose of $4 \mathrm{mg} / \mathrm{kg}$, followed by weekly doses of $2 \mathrm{mg} / \mathrm{kg}$. The ORR was $15 \%$ (CR 4\%, PR 11\%) with a median dura- 
tion of response of 9.2 months. The results of this trial led to the FDA approval of trastuzumab single agent therapy as a second-line treatment for HER2-positive metastatic breast cancer.

In the largest comparative trial, 469 patients were randomly assigned to receive standard chemotherapy or standard chemotherapy plus trastuzumab [41]. Patients without prior anthracycline therapy were treated with a combination of doxorubicin or epirubicin and cyclophosphamide (AC or EC, 138 women) alone or with trastuzumab (143 women). Patients with a history of anthracycline exposure were treated with paclitaxel alone (96 women) or paclitaxel with trastuzumab (92 women). Patients received trastuzumab weekly until the diseases progressed. Chemotherapy was administered every 3 weeks for at least six cycles. There were 118 responses in the chemotherapy/trastuzumab groups (50\%) compared to only 74 responses in the chemotherapy only group $(32 \%)$. Addition of trastuzumab to chemotherapy prolonged the median survival by 4.8 months, from 20.3 to 25.1 months, a result that is even more remarkable in light of the fact that $72 \%$ of patients originally randomized to chemotherapy treatment received trastuzumab after progression of their disease.

Recently, Genentech announced that, as part of a treatment regimen containing doxorubicin, cyclophosphamide and paclitaxel, the US FDA approved trastuzumab for the adjuvant treatment of HER2-positive node-positive breast cancer. Adjuvant therapy was given to women with earlystage (localized) breast cancer, who had initial treatment surgery with or without radiation therapy, with the goal of reducing the risk of cancer recurrence and/or the occurrence of metastatic disease.

Trastuzumab is generally well tolerated. Just like the cases with other mAbs, there were infusion-related reactions, which included fever, rigors, chills, nausea, dyspnoea and hypotension. The frequency of these events was reported to be around $40 \%$ in patients receiving the first dose, with a marked reduction to 5\% during the following administration. Symptoms usually responded well to interruption of the infusion or symptomatic treatment. An adverse event not anticipated in the pivotal combination chemotherapy trial was cardiac toxicity. Concurrent treatment with anthracycline, cyclophosphamide and trastuzumab significantly increased the risk of cardiac dysfunction, as compared with the treatment with only an anthracycline and cyclophosphamide [41]. For this reason, patients who are candidates for trastuzumab treatment should be carefully evaluated for cardiac function before and throughout the therapy.

\section{Bevacizumab (Avastin ${ }^{\circledR}$ )}

Avastin is a recombinant humanized antibody designed to bind to and inhibit VEGF, a protein that plays a critical role in tumor angiogenesis. Targeting tumor vasculature has become an increasingly attractive approach. Advantages of this approach include its applicability to various tumor types, low toxicity on normal tissues, low likelihood of resistance due to the genetic stability of endothelial cells that are not themselves transformed and good accessibility of the target structure to the antibody.

Bevacizumab received the FDA approval as a first-line treatment for metastasized colorectal cancer in combination with a 5-FU based regimen in 2004. Addition of the antibody to chemotherapy increased the ORR from $35 \%$ to $45 \%$ and prolonged median survival from 15.6 to 20.3 months in a randomized trial [42]. Bevacizumab administration could result in the development of gastrointestinal perforation and wound dehiscence, and even fatality in individual cases [43]. Gastrointestinal perforation, sometimes associated with intra-abdominal abscess, occurred throughout the treatment with Avastin and was not correlated to duration of exposure. The incidence of gastrointestinal perforation in patients receiving bolus-IFL with Avastin was 2\%. The typical presentation was reported as abdominal pain associated with symptoms such as constipation and vomiting. Gastrointestinal perforation should be included in the differential diagnosis of patients on Avastin presenting with abdominal pain. Avastin therapy should be terminated in patients with gastrointestinal perforation or wound dehiscence requiring medical intervention. The appropriate interval between termination of Avastin and subsequent elective surgery required to avoid the risks of impaired wound healing/wound dehiscence has not been determined. Serious or even fetal hemoptysis occurred in patients with non-small-cell lung cancer treated with chemotherapy and Avastin.

\section{Cetuximab (Erbitux ${ }^{\circledR}$ )}

Cetuximab is a chimeric $\mathrm{mAb}$ against the epidermal growth factor receptor (EGFR), which is expressed on a variety of malignant tumors such as non-small-cell lung cancer, head and neck or colon cancer.

A randomized phase II study carried out in Europe and presented at the 2003 American Society of Clinical Oncology conference confirmed earlier phase II evidence for the activity of cetuximab in patients with EGFR positive, irinotecan-refractory metastatic colorectal cancer. Cetuximab was given intravenously at a dose of $400 \mathrm{mg} / \mathrm{m}^{2}$ on week 1 , followed by $250 \mathrm{mg} / \mathrm{m}^{2}$ once a week thereafter. The investigators reported better results for re-treatment with cetuximab and irinotecan than with cetuximab alone. There were significant differences in response rate $(23 \%$ in the combination group vs $11 \%$ in the group treated 
with cetuximab alone), median time to progression (4.1 vs 1.5 months) and median overall survival time (8.6 vs 6.9 months) $[44,45]$. On the basis of these findings and those of previous studies, cetuximab received FDA approval in February 2004, for use in combination with irinotecan for patients who are refractory to irinotecan, or as a single agent for patients who are unable to tolerate irinotecan-based chemotherapy. Other indications are currently undergoing testing. One of the most promising cases is non-small-cell lung cancer where the addition of cetuximab to cisplatin/ vinorelbine in inoperable patients increased the response rate from $29 \%$ to $50 \%$ in a small randomized trial [46].

Toxic effects of cetuximab consist of infusion reactions and constitutional symptoms, as well as an acne-like skin rash that occurred in up to $75 \%$ of patients and was of grade 3 severity in $16 \%$ of patients. Development of this rash after treatment with cetuximab is a predictor of increased survival: the more intense the rash is, the greater the benefit is [47].

\section{Panitumumab (Vectibix $\left.{ }^{\circledR}\right)$}

Panitumumab is the first fully human monoclonal therapeutic antibody that targets the EGFR, a protein that plays an important role in cancer cell signaling. As a fully human antibody, panitumumab can be administered without any pre-medication and has the promise of decreased infusion reactions. Clinical studies have demonstrated that panitumumab had significant activity as a single agent and improved progression-free survival when compared with best supportive care (BSC). In a large, randomized, non-blind, multicenter phase III study in pre-treated adult patients with metastatic colorectal cancer and EGFR staining in $\geq 1 \%$ tumor cells, treatment with panitumumab at $6 \mathrm{mg} / \mathrm{kg}$ every 2 weeks plus BSC was significantly $(p<0.0001)$ more effective in improving progression-free survival than BSC alone; recipients of panitumumab plus BSC had a $46 \%$ lower disease progression rate than those receiving $\mathrm{BSC}$ alone after a median follow-up of 19 weeks [48]. Panitumumab at 6 $\mathrm{mg} / \mathrm{kg}$ every 2 weeks or $2.5 \mathrm{mg} / \mathrm{kg} / \mathrm{week}$, administered as a mono-therapy, produced partial response rates of $8-13 \%$ and stable disease rates of $21-30 \%$ in pre-treated patients with metastatic colorectal cancer in three non-comparative, multicenter phase II studies. Preliminary phase II results also suggested a potential role for panitumumab as a first-line therapy in combination with fluorouracil, folinic acid and irinotecan in patients with metastatic colorectal cancer [49]. Panitumumab received the FDA approval in September 2006 on the basis of these promising data at the treatment of patients with EGFR expressing metastatic colorectal cancer after disease progression on or following fluoropyrimidine-, oxaliplatin- and irinotecan-containing chemotherapy regimens.

Panitumumab was generally well tolerated. Grade $3 / 4$ skin-related toxicities were reported in $14 \%$ of patients receiving panitumumab plus BSC in the phase III study (vs $0 \%$ of patients receiving BSC alone). An analysis of pooled data found that high-affinity binding antibodies to panitumumab were detected in $<1 \%$ of patients.

\section{Strategies to improve anti-tumor efficacy of mAbs}

Numerous strategies for improving the efficacy of antitumor antibodies are now being tested, including:

(1) Enhancing effector functions such as improving antibody-dependent cellular cytotoxicity and/or complementdependent cytotoxicity by means of site-directed mutation or manipulation of antibody glycocylation [50].

(2) Direct arming of antibodies entails their covalent linkage to killing moieties, such as radionuclides or toxins (e.g. small molecules or proteins). Armed antibodies typically show more potent anti-tumor activity in pre-clinical tumor xenograft studies than their "naked" parents. The humanized anti-CD33 antibody-calicheamicin conjugate Mylotarg was approved for treatment of CD33-positive AML in first-relapse patients $\geq 60$ years old who are not candidates for cytotoxic chemotherapy. Arming antibodies with radionuclides enables them to kill bystander cells. Alternatively, arming antibodies with cytokines is intended to create high intra-tumor concentrations of cytokines to stimulate the anti-tumor immune response, while avoiding the toxicities associated with the cytokine delivery [51].

(3) Indirect arming of antibodies achieved by attaching engineered antibody fragments to the surface of liposomes loaded with drugs or toxins for tumor-specific delivery. Bispecific antibodies that bind to two different antigens can be pre-loaded with the cytotoxic agents before administration or alternatively pre-targeted to the tumor before delivery of the cytotoxic payload. Engineered antibody fragments can be attached to the surface of stealth liposomes for selective tumor targeting of large payloads of drugs, toxins or even DNA for gene therapy. Such large payloads offered an important potential advantage over direct antibody arming, in which only one or a few molar equivalents of the payload were attached per antibody to avoid compromising antigen binding, conjugate solubility or promoting aggregation [52, 53].

(4) Pre-targeting strategies aiming for the selective delivery of radionuclides to tumors or selective intra-tumor activation of pro-drugs, thereby diminishing the systemic toxicities of these cytotoxic agents. For pro-drug pretargeting, an antibody-fragment-enzyme fusion protein is typically allowed to localize to a tumor and be cleared off the system. A pro-drug is then administered and ide- 
ally converted to an active drug solely within the tumor. For radionuclide pre-targeting, an antibody-streptavidin conjugate is allowed to accrue within a tumor and is then used to capture the biotin-chelator-radionuclide complex $[54,55]$.

(5) The combination of anti-angiogenesis mAbs and chemotherapy resulting in synergistic anti-tumor efficacy [56]. Three distinct mechanisms may help to explain the chemosensitizing activity of anti-angiogenic mAbs: normalizing tumor vasculature, preventing rapid increase in tumor cell population and augmenting the antivascular effects of chemotherapy.

\section{Antibody gene therapy as a new strategy for cancer treatment}

Although nine mAbs have been approved by the FDA, wider application of $\mathrm{mAbs}$ is limited due to the following reasons: (1) high dose and purity required for antibody protein treatment increase the production cost; (2) the relatively large molecular weight of full-length antibody and high pressure within the tumor make it difficult for full-length antibody to penetrate into large-volume solid tumors, thus greatly reducing the therapeutic effect. It is expected that resolving these deficiencies would markedly increase the potential of antibody therapy in human cancer treatment. Therefore, antibody in vivo gene therapy is proposed as one of the best candidate approaches. The efforts of antibody gene therapy were reported by our lab in 2004 [57, 58] and subsequently by Jooss K's research group in 2005 [59].

In our study, we chose adenovirus as the antibody gene transfer vector for the following reasons [57, 58]: (1) adenovirus has been used in more than 5000 clinical patients without significant adverse effects and toxicity, exhibiting the conclusive safety and efficacy as an in vivo vector [60]; (2) adenoviral manufacture technologies are easy, convenient and simple; (3) adenovirus is the only commercial product approved in the world for gene therapy [61, 62]. We synthesized full-length anti-HER-2 antibody light chain and heavy chain genes $[57,58]$. The two genes were linked together with internal ribosome entry site and were under the control of the mCMV promoter. Recombinant antiHER-2 expressing adenovirus (Ad5-Tab), with the expression cassette inserted in the $E 1$ region of adenovirus 5 , was prepared in HEK293 cells. Administration of Ad5-Tab in vivo produced high serum concentrations of the full-length antibody, which has the same bioactivity as commercial trastuzumab. A single injection of Ad5-Tab resulted in effective therapeutic concentrations lasting for 4 weeks and a peak serum level of $>160 \mu \mathrm{g} / \mathrm{ml}$ at as early as day 7 after injection. The antibody produced by Ad-Tab in vivo demonstrated anti-tumor efficacy not only in small-volume but also in the large-volume tumors in HER-2 ${ }^{+} / \mathrm{SKOV}-3-$ inoculated nude mice. All these data demonstrated that: (1) this adenovirus-mediated antibody expressing system could be a new approach for antibody therapy; (2) the complicated, expensive and time-consuming antibody protein preparation and purification procedures could be replaced by using adenovirus as an antibody expression tool for its technical simplicity and low cost.

Fang et al. [59] also described a mAb delivery system that allows for continuous production of a full-length antibody at high-concentrations in vivo after gene transfer. They developed an antibody expression system that uses the foot-and-mouth-disease virus (FMDV)-derived 2A self-processing sequence to express the full-length antibody from a single open reading frame. Using an FMDV 2A sequence adjacent to a furin cleavage site to link the antibody heavy and light chain sequences, they engineered a mAb expression cassette that, in the context of AAV-mediated gene transfer, resulted in high levels of full-length, functional $\mathrm{mAbs}$ in vitro and in vivo. Sustained $\mathrm{mAb}$ serum levels of $1000 \mu \mathrm{g} / \mathrm{ml}$ were achieved in mice with a single administration of rAAV8 vector expressing DC101, an anti-angiogenic $\mathrm{mAb}$ targeting the vascular endothelial cell growth factor receptor-2 (VEGFR2 or Flk-1). The rAAV8mediated gene transfer of DC101 resulted in significant anti-tumor efficacy in two tumor models, demonstrating the generation of functional antibodies in vivo using this expression system.

\section{Strategy for improving antibody's anti-tumor effect by exploiting mesenchymal stem cells}

Another big hurdle for cancer antibody therapy is that the large molecule full-length antibody has great difficulty entering solid tumors, due to compacted stroma within the tumors and high intra-tumor pressure produced by lymphatic return barrier. Therefore, the anti-tumor efficacy of conventional antibody therapy is greatly reduced in treating large-volume solid tumors. Since mesenchymal stem cells (MSCs) can recognize the emitting signal from tumors and help to construct matrix or junction tissues for tumor growth, it would be an interesting attempt to use MSCs as a vehicle to deliver full-length antibody to tumors. In our study, the bone marrow derived primary mesenchymal stem cells (mBMSCs) were used as a vehicle to target tumor cells (our unpublished data). As MSCs cannot be effectively infected by commonly used adenovirus type 5 , a chimeric adenovirus with better infection efficiency on MSCs was constructed. We reconstructed an adenoviral variant Ad5-F35, which had its fiber knob and shaft from Ad35 and had its fiber tail and penton base from Ad5. The 
novel Ad5-F35 chimera demonstrated better infection ability compared with Ad5. The antibody gene expression cassette was released from Ad-Her and introduced into Ad5-F35 to produce Ad5-F35-Her. The MSCs infected with Ad5-F35-Her were administered by tail vein injection to treat pre-established lung metastatic SK-OV-3 tumors. The treatment group showed stronger anti-tumor efficacy compared with the group treated with non-infected MSCs $(p<0.001)$ (our unpublished data). There were no differences in lung weight and volume between the group treated with modified MSCs and the normal mice group without any disease $(p>0.05)$. Few necrosis foci and hemorrhage points were observed on the lung surface of mice treated with the modified MSCs. Some lung lobes were atrophic. Pathological examination showed micro-metastasis in lung tissues in only two out of nine mice in the group treated with the modified MSCs, but in all of the mice (9/9) treated with the commercial antibody Herceptin (our unpublished data). These results demonstrated that targeted therapy, using MSCs carrying a full-length antibody gene, could overcome the disadvantages of low antibody penetration into solid tumors, markedly enhancing the anti-tumor efficacy, and hence it has the potential to be developed into a safe, efficient, low cost and targeting therapeutic system.

\section{Potential side effects of cancer antibody gene therapy}

Although antibody gene therapy is less time consuming and more economical compared with traditional antibody protein therapy, its potential drawbacks are as follows: (1) antibodies from gene therapy are presumably produced in liver and lung cells that are efficiently infected by the viral vector. It is unknown whether some other somatic cells will also express the antibodies; (2) host antibodies against Adenovirus or AAV may decrease the anti-tumor efficacy of virus-mediated full-length antibody gene therapy; and (3) when this approach is applied to humans, the administration routes, the desired antibody gene expression time and possible inflammation response need to be investigated. There is still a long way to go before antibody gene therapy could be put into clinical use.

\section{Perspectives}

Antibodies have started to fulfill their promise as anticancer therapeutics with the nine antibodies now marketed as drugs in the US. The recent clinical and commercial success of anticancer antibodies, such as rituximab and trastuzumab, has generated great interest in antibody-based therapeutics for hematopoietic malignancies and solid tumors. Although, currently, there are a large number of agents in both early- and late-stages of clinical develop- ment, it is expected that only a handful will pass regulatory approval and become successful products. Full-length antibody cancer gene therapy will also prove to be a promising and feasible strategy for shortening the development process from pre-clinical research to clinical trials, avoiding the complicated procedures of antibody protein preparation and purification and reducing the treatment cost. If successfully implemented, it will become a revolutionary progress in antibody therapy for cancer. MSCs can also act as vehicles to bring the full-length antibody into the very inner parts of solid tumors, thus overcoming the poor penetration of solid tumors by the large molecule antibody. Given the likely lower toxicity of antibodies vs small molecules, the potential increase in efficacy by conjugation to radioisotopes and other cellular toxins, and the ability to characterize the target with clinical diagnostics to improve the drug's clinical performance, it is anticipated that current and future antibody therapeutics will find substantial roles either alone or in combination with other strategies for the treatment of cancer.

\section{References}

1 Kohler G, Milstein C. Continuous cultures of fused cells secreting antibody of pre-defined specificity. Nature 1975; 256:495-497.

2 Chester K, Pedley B, Tolner B, et al. Engineering antibodies for clinical applications in cancer. Tumour Biol 2004; 25:91-98.

3 Batra SK, Jain M, Wittel UA, Chauhan SC, Colcher D. Pharmacokinetics and biodistribution of genetically engineered antibodies. Curr Opin Biotechnol 2002; 13:603-608.

4 Ross J, Gray K, Schenkein D, et al. Antibody-based therapeutics in oncology. Expert Rev Anticancer Ther 2003; 3:107-121.

5 Stern M, Herrmann R. Overview of monoclonal antibodies in cancer therapy: present and promise. Crit Rev Oncol Hematol 2005; 54:11-29.

6 Osbourn J, Jermutus L, Duncan A. Current methods for the generation of human antibodies for the treatment of autoimmune diseases. Drug Discov Today 2003; 8:845-851.

7 Krauss J. Recombinant antibodies for the diagnosis and treatment of cancer. Mol Biotechnol 2003; 25:1-17.

8 Zangemeister-Wittke U. Antibodies for targeted cancer therapy - technical aspects and clinical perspectives. Pathobiology 2005; 72:279-286.

9 Kipriyanov SM, Le Gall F. Generation and production of engineered antibodies. Mol Biotechnol 2004; 26:39-60.

10 Berger M, Shankar V, Vafai A. Therapeutic applications of monoclonal antibodies. Am J Med Sci 2002; 324:14-30.

11 Qu Z, Griffiths GL, Wegener WA, et al. Development of humanized antibodies as cancer therapeutics. Methods 2005; 36:8495.

12 Harris M. Monoclonal antibodies as therapeutic agents for cancer. Lancet Oncol 2004; 5:292-302.

13 Pages F, Berger A, Camus M, et al. Effector memory T cells, early metastasis, and survival in colorectal cancer. N Engl J Med 2005; 353:2654-2666.

14 Peggs KS, Quezada SA, Korman AJ, Allison JP. Principles and 
use of anti-CTLA4 antibody in human cancer immunotherapy. Curr Opin Immunol 2006; 18:206-213.

15 Cassard L, Cohen-Solal JF, Galinha A, et al. Modulation of tumor growth by inhibitory $\mathrm{Fc}$ (gamma) receptor expressed by human melanoma cells. J Clin Invest. 2002; 110:1549-1557.

16 Mclaughlin P, Grillo-Lopez AJ, Link BK, et al. Rituximab chimeric anti-CD20 monoclonal antibody therapy for relapsed indolent lymphoma: half of patients respond to a four-dose treatment program. J Clin Oncol 1998; 16:1825-1833.

17 Piro LD, White CA, Grilllo-Lopez AJ, et al. Extended rituximab (anti-CD20 monoclonal antibody) therapy fro relapsed or refractory low grade or follicular non-Hodgkin's lymphoma. Ann Oncol 1999; 10:655-661.

18 Demidem A, Lam T, Alas S, Hariharan K, Hanna N, Bonavida B. Chimeric anti-CD20 (IDEC-C2B8) monoclonal antibody sensitizes B cell lymphoma cell line to cell killing by cytotoxic drugs. Cancer Biother Radiopharm 1997; 12:177-186.

19 Czuczman MS, Grillo-Lopez AJ, White CA, et al. Treatment of patients with low-grade B-cell lymphoma with the combination of chimeric anti-CD20 monoclonal antibody and CHOP chemotherapy. J Clin Oncol 1999; 17:268-276.

20 Czuczman M, Grillo-Lopez AJ, LoBuglio AI, et al. Patients with low-grade NHL treated with rituximab+CHOP experience prolonged clinical and molecular remission. ASH Annual Meeting Abstracts 2003; 102:1493.

21 Jaeger G, Neumeister P, Brezinschek R, et al. Rituximab (antiCD20 monoclonal antibody) as consolidation of first-line CHOP chemotherapy in patients with follicular lymphoma: a phase II study. Eur J Haematol 2002; 69:21-26.

22 Czuczman MS. Immunochemotherapy in indolent non-Hodgkin's lymphoma. Semin Oncol 2002; 29(Suppl 6):11-17.

23 Zinzani P. A randomized trial of fludarabine and mitoxantrone plus rituximab versus CHOP plus rituximab as first-line treatment in patients with follicular lymphoma. Blood 2001; 98:abstr 344.

24 Hainsworth JD, Litchy S, Burris HA III, et al. Rituximab as first-line and maintenance therapy for patients with indolent non-hodgkin's lymphoma. J Clin Oncol. 2002; 20:4261-4267.

25 Witzig TE. Efficacy and safety of $90 \mathrm{Y}$ ibritumomab tiuxetan (Zevalin) radioimmunotherapy for non-Hodgkin's lymphoma. Semin Oncol 2003; 30(Suppl 17):11-16.

26 Witzig TE, Gordon LI, Cabanillas F, et al. Randomized controlled trial of yttrium-90-labeled ibritumomab tiuxetan radioimmunotherapy versus rituximab immunotherapy for patients with relapsed or refractory low-grade, follicular, or transformed B-cell non-Hodgkin's lymphoma. J Clin Oncol 2002; 20:2453-2463.

27 Wiseman GA, Leigh BR, Erwin WD, et al. Radiation dosimetry results from a Phase II trial of ibritumomab tiuxetan (Zevalin) radioimmunotherapy for patients with non-Hodgkin's lymphoma and mild thrombocytopenia. Cancer Biother Radiopharm 2003; 18:165-178.

28 Kaminski MS, Zasadny KR, Francis IR, et al. Radioimmunotherapy of B-cell lymphoma with ${ }^{131} \mathrm{I}$ anti-B1 (anti-CD20) antibody. N Engl J Med 1993; 329:459-465.

29 Liu SY, Eary JF, Petersdorf SH, et al. Follow-up of relapsed B-cell lymphoma patients treated with iodine-131-labeled anti-CD20 antibody and autologous stem-cell rescue. J Clin Oncol 1998; 16:3270-3278

30 Gopal AK, Gooley TA, Maloney DG, et al. High-dose radio- immunotherapy versus conventional high-dose therapy and autologous hematopoietic stem cell transplantation for relapsed follicular non-Hodgkin lymphoma: a multivariable cohort analysis. Blood 2003; 102:2351-2357.

31 Sievers EL, Larson RA, Stadtmauer EA, et al. Efficacy and safety of gemtuzumab ozogamicin in patients with CD33-positive acute myeloid leukemia in first relapse. J Clin Oncol 2001; 19:32445324.

32 Estey EH, Thall PF, Giles FJ, et al. Gemtuzumab ozogamicin with or without interleukin 11 in patients 65 years of age or older with untreated acute myeloid leukemia and high-risk myelodysplastic syndrome: comparison with idarubicin plus continuous infusion, high-dose cytosine arabinoside. Blood 2002; 99:4343-4349.

33 Deangelo DJ, Liu D, Stone R, et al. Preliminary report of a phase 2 study of gemtuzumab ozogamicin in combination with cytarabine and daunorubicin in patients $<60$ years of age with de novo acute myeloid leukemia. Proc Am Soc Clin Oncol 2003; 22:abstr 2325.

34 Giles FJ, Kantarjian HM, Kornblau SM, et al. Mylotarg (gemtuzumab ozogamicin) therapy is associated with hepatic venoocclusive disease in patients who have not received stem cell transplantation. Cancer 2001; 92:406-413.

35 Keating MJ, Flinn I, Jain V, et al. Therapeutic role of alemtuzum$\mathrm{ab}($ Campath-1H) in patients who have failed fludarabine: results of a large international study. Blood 2002; 99:3554-3561.

36 Rai KR, Freter CE, Mercier RJ, et al. Alemtuzumab in previously treated chronic lymphocytic leukemia patients who also had received fludarabine. J Clin Oncol 2002; 20:3891-3897.

37 Osterborg A, Mellstedt H, Keating M. Clinical effects of alemtuzumab (Campath-1H) in B-cell chronic lymphocytic leukemia. Med Oncol 2002; 19 Suppl:S21-S26.

38 Faderl S, Thomas DA, O'Brien S, et al. Experience with alemtuzumab plus rituximab in patients with relapsed and refractory lymphoid malignancies. Blood 2003; 101:3413-3415.

39 Keating MJ, Cazin B, Coutre S, et al. Campath-1H treatment of T-cell prolymphocytic leukemia in patients for whom at least one prior chemotherapy regimen has failed. J Clin Oncol 2002; 20:205-213.

40 Cobleigh MA, Vogel CL, Tripathy D, et al. Multinational study of the efficacy and safety of humanized anti-HER2 monoclonal antibody in women who have HER2-overexpressing metastatic breast cancer that has progressed after chemotherapy for metastatic disease. J Clin Oncol 1999; 17:2639-2348.

41 Slamon DJ, Leyland-Jones B, Shak S, et al. Use of chemotherapy plus a monoclonal antibody against HER2 for metastatic breast cancer that overexpresses HER2. N Engl J Med 2001; 344:783792.

42 Hurwitz H, Fehrenbacher L, Cartwright T, et al. Bevacizumab (a monoclonal antibody to vascular endothelial growth factor) prolongs survival in first-line colorectal cancer (CRC): results of a phase III trial of bevacizumab in combination with bolus IFL (irinotecan, 5-fluorouracil, leucovorin) as first-line therapy in subjects with metastatic CRC. Proc Am Soc Clin Oncol 2003; 22:abstr 3646.

43 Hurwitz H, Fehrenbacher L, Novotny W, et al. Bevacizumab plus irinotecan, fluorouracil, and leucovorin for metastatic colorectal cancer. N Engl J Med 2004; 350:2335-2342.

44 Cunningham D, Humblet Y, Siena S, et al. Cetuximab (C225) alone or in combination with irinotecan (CPT-11) in patients with 
epidermal growth factor receptor (EGFR)-positive, irinotecanrefractory metastatic colorectal cancer (MCRC). Proc Am Soc Clin Oncol 2003; 22:abstr 1012.

45 Cunningham D, Humblet Y, Siena S, et al. Cetuximab monotherapy and cetuximab plus irinotecan in irinotecan-refractory metastatic colorectal cancer. N Engl J Med 2004; 351:337345.

46 Gatzemeier U, Rosell R, Ramlau R, et al. Cetuximab (C225) in combination with cisplatin/vinorelbine vs. cisplatin/vinorelbine alone in the first-line treatment of patients (pts) with epidermal growth factor receptor (EGFR) positive advanced non-small-cell lung cancer (NSCLC). Proc Am Soc Clin Oncol 2003; 22:abstr 2582.

47 Saltz LB, Meropol NJ, Loehrer PJ Sr, Needle MN, Kopit J, Mayer RJ. Phase II trial of cetuximab in patients with refractory colorectal cancer that expresses the epidermal growth factor receptor. J Clin Oncol. 2004; 22:1201-1208.

48 Van Cutsem E. Challenges in the use of epidermal growth factor receptor inhibitors in colorectal cancer. Oncologist 2006; 11:1010-1017.

49 Wainberg Z, Hecht JR. Panitumumab in colon cancer: a review and summary of ongoing trials. Expert Opin Biol Ther 2006; 6:1229-1235.

50 Carter P. Improving the efficacy of antibody-based cancer therapies. Nat Rev Cancer 2001; 1:118-129.

$51 \mathrm{Wu}$ AM, Senter PD. Arming antibodies: prospects and challenges for immunoconjugates. Nat Biotechnol 2005; 23:1137-1146.

52 Sharkey RM, Goldenberg DM. Targeted therapy of cancer: new prospects for antibodies and immunoconjugates. CA Cancer $\mathrm{J}$ Clin 2006; 56:226-243.

53 McCarron PA, Olwill SA, Marouf WM, Buick RJ, Walker B, Scott CJ. Antibody conjugates and therapeutic strategies. Mol Interv 2005; 5:368-380.

54 Lambert JM. Drug-conjugated monoclonal antibodies for the treatment of cancer. Curr Opin Pharmacol 2005; 5:543-549.

55 Lin MZ, Teitell MA, Schiller GJ. The evolution of antibodies into versatile tumor-targeting agents. Clin Cancer Res 2005; 11:129-138.

56 Kerbel RS. Antiangiogenic therapy: a universal chemosensitization strategy for cancer. Science 2006; 312: 1171-1175.

57 Guo MG, Jiang MH, Yang Q, et al. Gene therapy for ovarian cancers by adenovirus-mediated complete antibody gene. Zhonghua yi xue za zhi 2004; 84:1147-1151

58 Jiang MH, Shi WF, Zhang Q, et al. Gene therapy for Her-2 over-expression cancers using adenovirus mediated full-length anti-Her2 antibody. Clin Cancer Res 2006; 12:6179-6185.

59 Fang J, Qian JJ, Yi S, et al. Stable antibody expression at therapeutic levels using the 2A peptide. Nat Biotechnol 2005; 23:584-590.

60 Ghosh SS, Gopinath P, Ramesh A. Adenoviral vectors: a promising tool for gene therapy. Appl Biochem Biotechnol 2006; 133:9-29.

61 Goncalves MA, de Vries AA. Adenovirus: from foe to friend. Rev Med Virol 2006; 16:167-186.

62 Relph KL, Harrington KJ, Pandha H. Adenoviral strategies for the gene therapy of cancer. Semin Oncol 2005; 32:573-582. 